\title{
High Loss of Plant Phylogenetic and Functional Diversity Due to Simulated Extinctions of Pollinators and Seed Dispersers in a Tropical Savanna
}

\author{
Marcus V. Cianciaruso ${ }^{1 *}$, Marco Antônio Batalha² \& Owen L. Petchey ${ }^{3}$
}

${ }^{1}$ Departamento de Ecologia, Instituto de Ciências Biológicas - ICB, Universidade Federal de Goiás - UFG, Goiânia, GO, Brazil

${ }^{2}$ Departamento de Botânica, Universidade Federal de São Carlos - UFSCar, São Carlos, SP, Brazil

${ }^{3}$ Institute for Evolutionary Biology and Environmental Studies, University of Zurich, Zurich, Switzerland

\begin{abstract}
Identification of the factors driving extinctions is fundamental to conservation biology. Here, we assessed the likely consequences of extinction of pollinators and dispersers for phylogenetic and functional diversity of savanna woody plant species. Loss of phylogenetic diversity was greater than expected by chance in simulated extinctions of moth- and beetle-pollinated species, and bird- and mammal-dispersed species. In extinction simulations of bee and bat-pollinated species, the loss of functional diversity was greater than expected by chance. Two main features could drive greater loss of biodiversity than expected by chance: loss of clumped species and loss of very unique species. Pollination and dispersal modes must be taken into account in conservation plans or ecological restoration strategies, since communities may be differentially vulnerable to the loss of one of these processes. Both functional and phylogenetic components of biodiversity should be considered, as consequences of extinctions for one are not necessarily the same as for the other.
\end{abstract}

Key words: Cerrado, Conservation, Functional Traits, Evolutionary History, Originality.

\section{Introduction}

In the last decade, concerns about biodiversity loss have dominated conservation biology. Biodiversity loss may lead to irreversible breakages in community functioning, including biogeochemical cycles, climate control, decomposition, pest control, and pollination (Loreau et al. 2002). Habitat disruption and fragmentation are likely to affect plant-animal mutualisms, especially pollination and seed dispersal (see Quesada et al. 2003). Local extinctions of pollinators and dispersers are of great concern because, since they move genetic material (within pollen or seeds) among fragments, they can reduce the negative effects of habitat fragmentation (Young et al. 1996). Anthropogenic disturbances, for example habitat change, increase the probability that extinction overcomes immigration in local populations, ultimately leading to an increase in the number of species that go extinct globally (Ceballos \& Erlich 2002).

Traditionally, biodiversity has been quantified by the number of species occurring in a given site, but one of

*Send correspondence to: Marcus Cianciaruso Departamento de Ecologia, Instituto de Ciências Biológicas - ICB, Universidade Federal de Goiás - UFG, CP 131, CEP 74001-970, Goiânia, GO, Brazil E-mail: cianciaruso@gmail.com the shortcomings of this approach is that it ignores the differences among species. To overcome this limitation, phylogenetic diversity (e.g., Faith 1992), which takes into account evolutionary relatedness, and functional diversity (Petchey \& Gaston 2006), which takes into account functional differences among species, can be used to investigate the consequences of human disturbances and, thus, empower policies of biological conservation (Pavoine et al. 2005). Whereas, by definition, the phylogenetic diversity approach has a more evolutionary focus, the functional diversity approach is based on the idea that species effects on ecosystem processes or their responses to the environment can be accessed by their ecological traits (Violle et al. 2007).

Because species loss is usually a non-random process (Purvis et al. 2000), it is crucial to identify the factors driving it and also to estimate the vulnerability of natural communities to extinctions (Purvis et al. 2000; Quesada et al. 2003). One way to understand the effect of extinctions on phylogenetic and functional diversity is through simulated extinctions, in which communities are disassembled using some a priori criteria (Purvis et al. 2000). These criteria represent distinct properties that are related to the probability of a species to face extinction: species may 
be lost according to range size (Malcolm et al. 2006), a particular trait (Cardillo et al. 2005), or via co-extinctions in mutualistic networks (Rezende et al. 2007).

Here we explored the consequences of extinction of pollinators and seed dispersers on phylogenetic and functional diversities of savanna woody plants. Our rationale was that the extinction of a particular vector (for example, moths) would strongly affect all the plant species that are exclusively pollinated by this vector (in our example, those exclusively pollinated by moths), and these plants would ultimately go extinct. We did co-extinction simulations where groups of plants were extinct based on the hypothetical extinction of their pollinators or dispersers. By doing so, we answered the following question: does the extinction of a given plant group due to the extinction of its pollinator or disperser result in a greater loss of phylogenetic or functional diversity than one may expect solely by chance?

\section{Material and methods}

\section{Study area}

We used data available on savanna (cerrado) woody species which occur in Emas National Park ('Emas'), one of the largest and most important reserves in the Cerrado domain. In 'Emas' open savanna prevails, covering 68.1\% of the park. For more details on the study area see Batalha \& Martins (2002).

\section{Phylogenetic data}

We constructed a phylogeny (Appendix A), for all 164 savanna woody species which occur in 'Emas', with the Phylomatic software (Webb \& Donoghue 2005). Phylogenetic distances among species were estimated from the megatree 'R20120829.new' which is based on the APGIII (APG 2009) classification. We used node ages proposed by Bell et al. (2010) and placed undated nodes in the tree evenly between dated nodes with the BLADJ algorithm in Phylocom (Webb et al. 2008). We estimated phylogenetic diversity using the PD index, a measure that uses the sum of branch lengths of the phylogenetic tree to assess species phylogenetic relatedness (Faith 1992).

\section{Functional data}

Because we did not have functional information for all species, we gathered data available on as many species as possible. Here functional data were collected for 50 species occurring in savanna woodlands within the park (Silva \& Batalha 2008). To estimate functional diversity we used 11 traits related to important community functions and processes (Appendix B). We used a measure of functional diversity based on the dispersion of species in trait space (FD; Petchey \& Gaston 2006). To construct the functional dendrogram we used Gower distance and UPGMA clustering.

\section{Extinction simulations}

Using literature data (Appendix C) we assigned each plant species according to its main pollinator - small bees, large bees, beetles, moths, bats, birds, flies, or wind - and seed disperser - ants, mammals, birds, wind or self-dispersing. We considered a species as a generalist when it had two or more main vectors indicating it is not strictly dependent on a single group of pollinators or dispersers. Only plant species pollinated or dispersed by biotic vectors were used in the extinction simulations.

For each simulated extinction, we calculated the remaining plant PD and FD after the hypothetical loss of a given group of pollinator or disperser species. We compared the observed values to their respective null distributions generated by Monte Carlo procedures (1,000 iterations), in which the same number of species were removed at random. In that way, it was possible to answer whether the extinction of a group of plants resulted in a greater loss of PD or FD than a random extinction of the same number of species. Also, to further investigate the patterns of extinction, we calculated the mean phylogenetic and functional originality (QEbased index, Pavoine et al. 2005) of the species within each pollinator and disperser group, and compared this with the average originality of all species. Originality is a measure of how distinct a species is when compared with the other species in a phylogenetic tree (Pavoine et al. 2005), reflecting the isolation of a species on all levels of the tree and thus indicating a unique evolutionary pathway. The same rationale can be applied to estimate functional diversity with a dendrogram-based measure. We conducted all analyses in R (R Development Core Team 2011).

\section{Results}

\section{Loss of phylogenetic diversity}

Concerning pollination, we found 59 generalist plant species, 37 pollinated by large bees, 29 by small bees, 14 by moths, 10 by beetles, six by birds, five by bats, three by wind, and one by flies. In relation to seed dispersal, we found 35 generalist- and 16 self-dispersed species, 50 species dispersed by wind, 44 by birds, 18 by mammals, and one by ants (Table 1; Appendix C).

Simulated extinctions of moth- and beetle-pollinated species resulted in a greater loss of PD than expected by chance, and there were no significant PD losses for the other pollinators (Table 1). Indeed, moth-, beetle-, and bat-pollinated species had higher phylogenetic originality (Figure 1a), but in the case of bat-pollinated species PD loss was not significant (Table 1). Simulated extinctions of bird-dispersed and mammal-dispersed species resulted in a greater loss of PD than expected by chance, but there was no significant PD loss for generalist species (Table 1). 
Table 1. Observed phylogenetic diversity (PD) that remained after the removal of a given group of plant species according to different extinction simulations, and the mean of 1,000 random PD values for each simulation. Values in bold are significant (lower remaining PD than expected by chance) at $\alpha=0.05$, one tailed test.

\begin{tabular}{lcccc}
\hline \multicolumn{1}{c}{ Simulated extinction } & Number of species & $\begin{array}{c}\text { Observed remaining } \\
\text { PD }\end{array}$ & $\begin{array}{c}\text { Simulated remaining } \\
\text { PD (mean) }\end{array}$ & $P$ \\
\hline $\begin{array}{l}\text { plants pollinated by } \\
\text { small bees }\end{array}$ & 29 & 60.58 & & 0.059 \\
large bees & 37 & 60.15 & 60.22 & 0.735 \\
moths & 14 & $\mathbf{6 0 . 4 9}$ & 70.16 & $\mathbf{0 . 0 0 1}$ \\
bats & 5 & 70.44 & 70.77 & 0.068 \\
beetles & 10 & $\mathbf{6 5 . 1 6}$ & 78.40 & $\mathbf{0 . 0 0 6}$ \\
birds & 6 & 70.19 & 70.56 & 0.658 \\
generalist & 59 & 48.47 & 50.19 & 0.270 \\
& & & & \\
plants dispersed by & & & 70.17 & $\mathbf{0 . 0 0 1}$ \\
mammals & 18 & $\mathbf{6 0 . 4 2}$ & 60.27 & $\mathbf{0 . 0 0 1}$ \\
Birds & 44 & $\mathbf{5 0 . 6 4}$ & 60.47 & 0.217 \\
\hline generalist & 35 & 60.28 & & \\
\hline
\end{tabular}

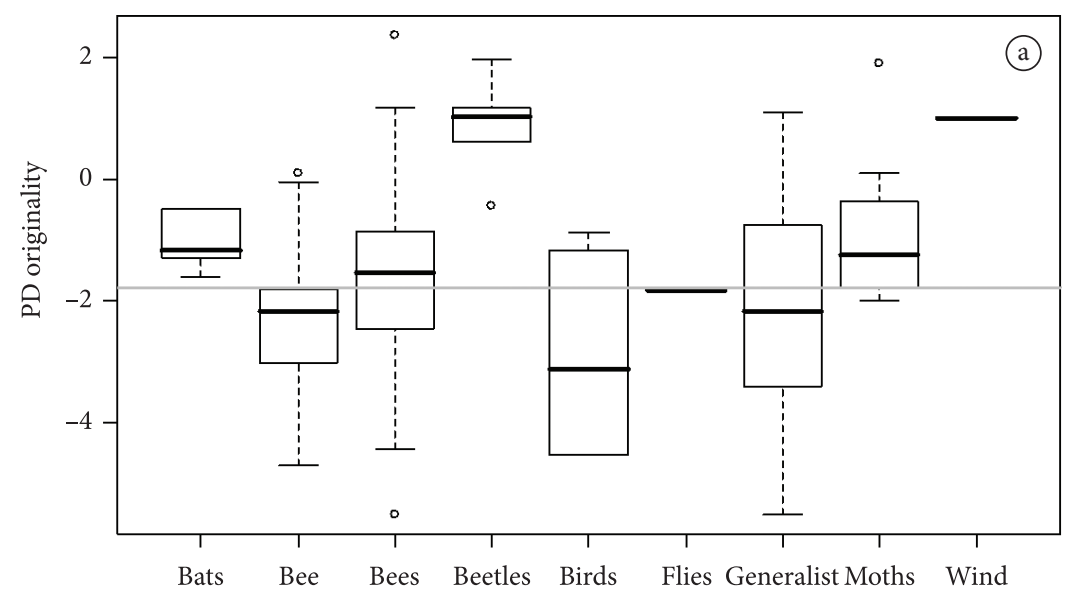

Pollination vector

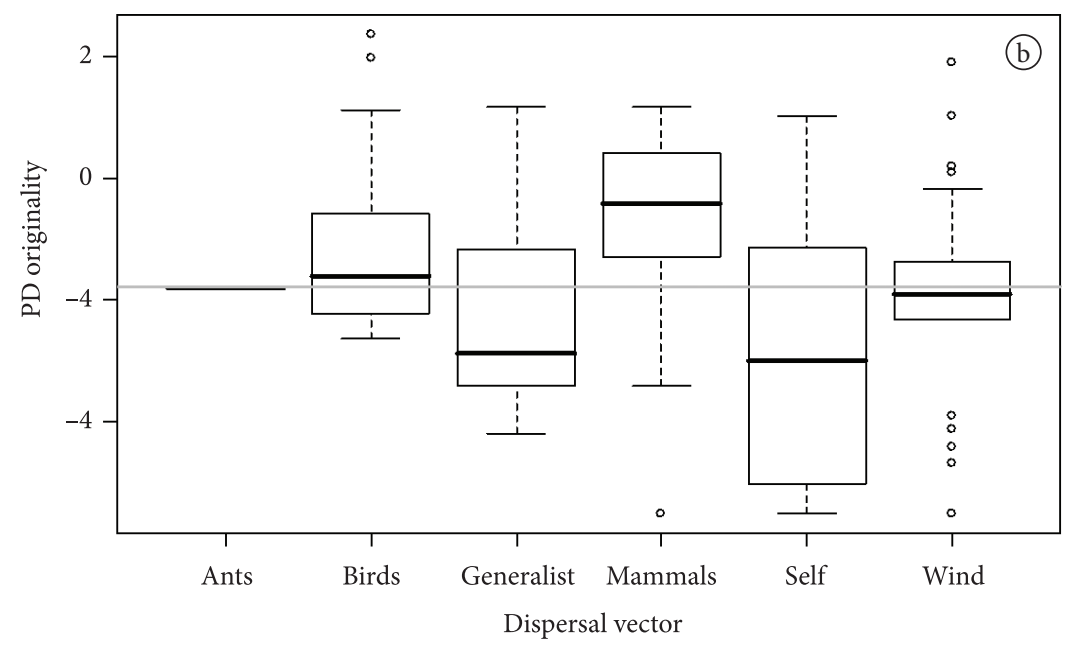

Figure 1. Phylogenetic originality of the species within each pollination (a) and dispersal (b) mode. Box-plots indicate the median, quartiles, extreme values, and outliers (open circles). The grey line is the average originality for all species analysed. Values were logtransformed due to the lack of normality. 
Only 16 species accounted for most of the phylogenetic originality within our dataset (Appendix D). Loss of bird-dispersed species resulted in the loss of five whole plant families (Nyctaginaceae, Araliaceae, Ochnaceae, Erythroxylaceae and Salicaceae), three rich genera (Miconia, Eugenia and Psidium), and two species with high originality (Aiouea trinervis and Virola sebifera). Loss of entire clades was less pronounced when mammal-dispersed species went extinct, but loss of species with high originality (those belonging to the genera Allagoptera, Attalea, Emmotum, Solanum) contributed to the pattern we found (Figure $1 \mathrm{~b}$, Appendix D).

\section{Loss of functional diversity}

Concerning pollination, we found 21 generalist species, 10 pollinated by large bees, seven by small bees, six by moths, three by bats, two by beetles, and one by birds. In relation to dispersal, we found four generalist- and four self-dispersed species, 17 species dispersed by wind, 14 by birds, 10 by mammals, and one by ants (Table 2 ).

Simulated extinctions of plants pollinated by small bees and plants pollinated by bats resulted in a greater loss of FD than expected by chance; but there were no significant FD losses for the other simulations (Table 2). On average bee-pollinated species were more unique whereas bat-pollinated presented great variability in originality values (Figure 2a). Finally, simulated extinction of bird- and mammal-dispersed species, as well as generalists, did not result in a greater loss of FD than expected by chance (Table 2). Accordingly, none of these groups had higher originality than the average (Figure $2 \mathrm{~b}$ ). About $30 \%$ of all species (16 species) were responsible for $65 \%$ of all originality values pooled together (Appendix E). Species pollinated by small bees and bats were amongst those with high originality values. For example, Allagoptera leucocalix, Machaerium acutifolium, and Bauhinia rufa (Appendix E).

\section{Discussion}

Extinction of certain groups of plant species led to a higher biodiversity loss than expected by chance. However, the simulated loss of pollinators and dispersers led to different changes of plant phylogenetic and functional diversity, depending on the animal group extinguished. Evolutionary history can be preserved in the face of substantial species losses if extinction is random with respect to the phylogenetic position of species, but usually this is not the case (Purvis et al. 2000). Extinction of species that belong to the same clade is one possible explanation to a higher loss of phylogenetic diversity than expected by chance (Purvis et al. 2000). In this case, no closely related species remains in the phylogeny - a whole evolutionary branch is lost. Another process that could produce a great loss of phylogenetic diversity is the preferential loss of species with high originality values. Both processes mentioned above appear to explain the extinction patterns observed. The great loss of evolutionary history observed in the simulated extinction of beetle-pollinated plants may be explained by the loss of species (Annona crassiflora and Duguetia furfuracea) that belong to the same ancient family (Annonaceae), and thus contributed significantly to the phylogenetic diversity of the whole community. In our dataset, species of Annonaceae were amongst the most original (Appendix D). So in this case an entire clade composed of very original species was lost. The greater loss of phylogenetic diversity when moth-pollinated species were extinguished was mainly explained by the loss of closely related species (i.e. an entire clade comprised by all Apocynaceae and Strychnos pseudoquina), but also by the loss of Roupala montana, which had a high originality value (Figure 1a, Table 1).

Table 2. Observed functional diversity (FD) that remained after the removal of a given group of plant species according to different extinction simulations, and the mean of 1,000 random FD values for each simulation. Values in bold are significant (lower remaining FD than expected by chance) at $\alpha=0.05$, one tailed test.

\begin{tabular}{lcccc}
\hline \multicolumn{1}{c}{ Simulated extinction } & $\begin{array}{c}\text { Number of } \\
\text { species }\end{array}$ & Observed remaining FD & $\begin{array}{c}\text { Simulated remaining } \\
\text { FD (mean) }\end{array}$ & $P$ \\
\hline plants pollinated by & & & & \\
small bees & 7 & 0.85 & 0.89 & $\mathbf{0 . 0 0 7}$ \\
large bees & 10 & 0.86 & 0.91 & 0.874 \\
moths & 6 & 0.91 & 0.96 & 0.601 \\
bats & 3 & 0.93 & 0.97 & $\mathbf{0 . 0 4 1}$ \\
beetles & 2 & 0.97 & 0.98 & 0.512 \\
birds & 1 & 0.98 & 0.65 & 0.188 \\
generalist & 21 & 0.67 & & 0.602 \\
plants dispersed by & & & & 0.84 \\
mammals & 10 & 0.82 & 0.77 & 0.086 \\
birds & 14 & 0.77 & 0.93 \\
generalist & 4 & 0.94 & 0.451 \\
\hline
\end{tabular}



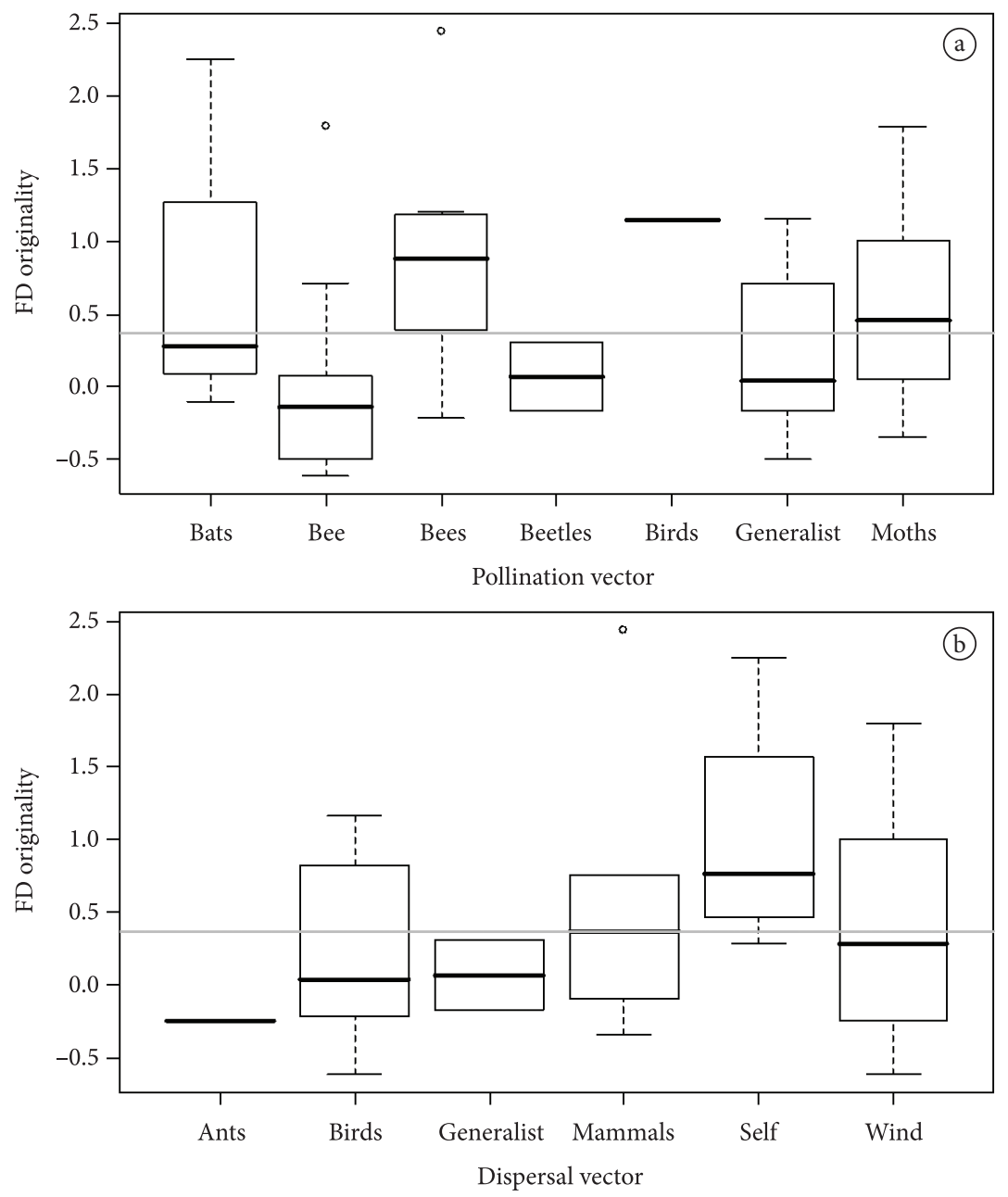

Figure 2. Functional originality of the species within each pollination (a) and dispersal (b) mode. Box-plots indicate the median, quartiles, extreme values, and outliers (open circles). The gray line is the average originality for all species analysed. Values were logtransformed due to lack of normality.

Phylogenetic diversity was more vulnerable to the loss of dispersers than pollinators. This is an important difference, because the local extinction of mammal and bird species is much more likely than the extinction of beetles or moths, since the former are the most vulnerable to disturbances such as fragmentation and habitat loss (Marini \& Garcia 2005). For example, in fragmented landscapes of Atlantic Forest, plants pollinated by mammals and birds were the first to disappear as a consequence of the extinction of their pollinators (Girão et al. 2007). In addition, the richness of moths and beetles in Brazil is orders of magnitude higher than that of mammals and birds, which could imply a higher degree of ecological redundancy in terms of pollination. Additionally, we must take into account that almost all generalist plants are dispersed both by mammals or birds. Because seed dispersal is vital for survival and regeneration of plant populations (Young et al. 1996), the disappearance of birds and mammals would ultimately lead to the disappearance of plants dispersed by those vectors in savanna woodlands within 'Emas', resulting in a great loss of phylogenetic diversity.
When interested in how similar species were in respect to their functional traits, we found a different picture. Whereas the loss of plant species pollinated by small bees and by bats led to a higher loss of functional diversity than expected by chance, the loss of biotic dispersed plant species resulted in a loss of functional diversity that was not different from chance. The explanation for the high loss of functional diversity when plant pollinated by small bees and bats went extinct follows the same rationale discussed before for the loss of phylogenetic diversity. Plants pollinated by small bees and by bats were functionally more original than the average (Figure 2a). A species with high functional originality would be more unique in its functional traits and would also be relatively more complementary to the other species within a community. Losing these species would represent a higher loss of complementarity within the community studied (Petchey \& Gaston 2006). The importance of bats as pollinators rests on their ability to carry pollen over short or long distances promoting outcrossing between unrelated trees and thus gene flow in fragmented landscapes (Quesada et al. 2003). In addition, bats are key pollinators 
of several economically important species in the Neotropics (Quesada et al. 2003). An example is Caryocar brasiliense (pequi), a typical cerrado tree that produce fruits widely used as food resource, but also by cosmetics industries and in the popular medicine.

Small bees are the main pollinators in the Brazilian savanna (Gottsberger \& Silberbauer-Gottsberger 2006). Major threats to native bees are also habitat fragmentation and the introduced honeybee Apis mellifera (Roubik 1978). It is well documented that this species is increasing its abundance and range area within the Brazilian Cerrado (Gottsberger \& Silberbauer-Gottsberger 2006). A. mellifera is much more aggressive than native bees and can potentially displace other bee populations and outcompete them for foraging sites (Roubik 1978). This is worrisome, not only because bees are the main pollinators in cerrado, but also because about $50 \%$ of the cerrado woody species are self-incompatible (Gottsberger \& Silberbauer-Gottsberger 2006). Because cerrado plants pollinated by small bees are very complementary in their functional traits the loss of small bees may have negative consequences to the functional diversity of the studied plant assemblages.

\section{Conclusions}

Two main features may drive greater loss of phylogenetic or functional diversities than expected by chance: loss of clumped species (which leads to the loss of entire clades or groups) as already observed by Purvis et al. (2000), and loss of very unique species. Conservation of the combination of species representing the highest originality should be prioritised. From a conservation standpoint, the originality of a species should be one of the criteria used to decide which species should receive priority attention (Pavoine et al. 2005).

We found that species relatedness cannot be used as a proxy for their functional relationships because we found distinct results depending on which biodiversity component was used. This means that closely related species may or may not be more functionally similar than less related species, and contrasts with the common assumptions of phylogenetic conservation of traits. Minimising the loss of phylogenetic and functional diversities may therefore require different actions. The approach we used here is a useful, cheap, and practical way to predict the fragility of natural communities to extinctions. It could be used as guideline to future conservation planning, biological monitoring, and restoration activities.

\section{Acknowledgements}

Marco Mello, Rafael Loyola, and Leandro Duarte made useful comments in early versions of this manuscript. Marco Batalha and Marcus Cianciaruso receive a productivity grant from CNPq. Marcus Cianciaruso research is funded by CNPq (\#476599/2012-1) and FAPEG (\#006/2009).

\section{References}

Angiosperm Phylogeny Group - APG, 2009. An update of the Angiosperm Phylogeny Group classification for the orders and families of flowering plants: APG III. Botanical Journal of the Linnean Society, 161:105-121. http://dx.doi. org/10.1111/j.1095-8339.2009.00996.x

Batalha MA \& Martins FR, 2002. The vascular flora of the cerrado in Emas National Park (Goiás, central Brazil). Sida, 20:295-311.

Bell CD, Soltis DE \& Soltis PS, 2010. The age and diversification of the angiosperms re-revisited. American Journal of Botany, 97:1296-1303. http://dx.doi.org/10.3732/ajb.0900346

Cardillo M et al., 2005 Multiple causes of high extinction risk in large mammal species. Science, 309:1239-1241. http:// dx.doi.org/10.1126/science.1116030

Ceballos G \& Ehrlich PR, 2002. Mammal population losses and the extinction crisis. Science, 296:904-907. http://dx.doi. org/10.1126/science.1069349

Faith DP, 1992. Conservation evaluation and phylogenetic diversity. Biological Conservation, 61:1-10. http://dx.doi. org/10.1016/0006-3207(92)91201-3

Girão LC et al., 2007. Changes in Tree Reproductive Traits Reduce Functional Diversity in a Fragmented Atlantic Forest Landscape. PlosOne, 2:E908. http://dx.doi.org/10.1371/ journal.pone.0000908

Gottsberger G \& Silberbauer-Gottsberger I, 2006. Life in the cerrado - a South American tropical seasonal ecosystem. Reta Verlag, Ulm. v. 2. Pollination and seed dispersal.

Loreau M, 2002. Biodiversity loss and the maintenance of our life-support system. In: Steffen W et al. (eds.). Challenges of a changing Earth. Berlin: Springer. p. 169-173. http:// dx.doi.org/10.1007/978-3-642-19016-2_32

Malcolm JR et al., 2006 Global warming and extinctions of endemic species from biodiversity hotspots. Conservation Biology, 20:538-548. http://dx.doi. org/10.1111/j.1523-1739.2006.00364.x

Marini MÂ \& Garcia FI, 2005. Bird Conservation in Brazil. Conservation Biology, 19:665-671. http://dx.doi. org/10.1111/j.1523-1739.2005.00706.x

Pavoine S, Ollier S \& Dufour AB, 2005. Is the originality of a species measurable? Ecology Letters, 8:579-586. http:// dx.doi.org/10.1111/j.1461-0248.2005.00752.x

Petchey OL \& Gaston KJ, 2006. Functional diversity, back to basics and looking forward. Ecology Letters, 9:741-758. http://dx.doi.org/10.1111/j.1461-0248.2006.00924.x

Purvis A et al., 2000. Nonrandom extinction and the loss of evolutionary history. Science, 288:328-330. http://dx.doi. org/10.1126/science.288.5464.328

Quesada M et al., 2003. Effects of habitat disruption on the activity of nectarivorous bats (Chiroptera: Phyllostomidae) in a dry tropical forest, implications for the reproductive success of the neotropical tree Ceiba grandiflora. Oecologia, 135:400-406. 
R Development Core Team, 2011. R: A Language and Environment for Statistical Computing. Vienna: R Foundation for Statistical Computing. Available from: $<$ http:www.r-project.org $>$.

Rezende EL et al., 2007. Non-random coextinctions in phylogenetically structured mutualistic networks. Nature, 448:925-928. http://dx.doi.org/10.1038/nature05956

Roubik DW, 1978. Competitive interactions between Neotropical pollinators and Africanized honey bees. Science, 201:10301032. http://dx.doi.org/10.1126/science.201.4360.1030

Silva DM \& Batalha MA, 2008. Soil-vegetation relationships in cerrados under different fire frequencies. Plant and Soil, 311:87-96. http://dx.doi.org/10.1007/s11104-008-9660-y
Violle C et al., 2007. Let the concept of trait be functional! Oikos, 116:882-892. http://dx.doi. org/10.1111/j.0030-1299.2007.15559.x

Webb CO \& Donoghue MJ, 2005. Phylomatic: tree assembly for applied phylogenetics. Molecular Ecology Notes, 5:181-183. http://dx.doi.org/10.1111/j.1471-8286.2004.00829.x

Webb CO et al., 2008. Phylocom: software for the analysis of phylogenetic community structure and trait evolution. Bioinformatics, 24:2098-2100. http://dx.doi.org/10.1093/ bioinformatics/btn358

Young A, Boyle T \& Brown T, 1996. The population genetic consequences of habitat fragmentation for plants. Trends in Ecology and Evolution, 11:413-418. http://dx.doi. org/10.1016/0169-5347(96)10045-8

Received: November 2012

First Decision: December 2012

Accepted: March 2013 